Copyright (C) 2016 by Academic Publishing House Researcher

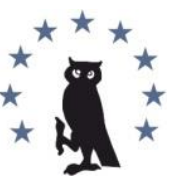

Published in the Russian Federation

European Researcher

Has been issued since 2010.

ISSN 2219-8229

E-ISSN 2224-0136

Vol. 112, Is. 11, pp. 567-580, 2016

DOI: 10.13187/er.2016.112.567

www.erjournal.ru

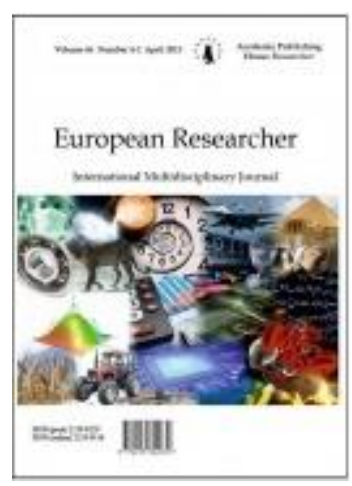

UDC 339.137.2:72+336

\title{
International Competitiveness of Banks in the Formation of a New Financial Infrastructure
}

\author{
Igor O. Jusko a ${ }^{\text {, * }}$ \\ a Kyiv National Economic University after Vadym Hetman, Ukraine
}

\begin{abstract}
The article describes the factors forming a new financial infrastructure. Studied the key factors of the international competitiveness of banks in the conditions of formation of a new financial infrastructure. The effect of strengthening macro-prudential banking supervision, the wide use of information and technology innovation, financial innovation on the formation of a new financial infrastructure, which has implications for the international competitiveness of banks in the global financial market. On the basis of generalization of modern theoretical developments are designed integral competitiveness indicators of the banks that have a high cross-jurisdictional activity. Particular attention is paid to the effectiveness of bank management.

Keywords: financialization, globalization, financial infrastructure, competitiveness, systemically important banks, major banks, blokchain technolgy, transactions.

\section{1. Введение}

Неотъемлемой составляющей глобализации является влияние информационноинновационных технологий, которое определило трансформацию мирового финансового рынка в направлении виртуализации и снижение связи между темпом роста финансового капитала и реального сектора (так называемая финансиализация). Финансиализация является объективным процессом, который предоставляет нестабильность глобального развития, имеет драматические последствия в виде региональных и мировых финансовоэкономических кризисов. Высоко рисковый характер банковской деятельности в условиях транснационализации требует постоянного совершенствования системы банковского надзора на национальном и наднациональном уровнях. Внедрение обновленных принципов регулирования стабильности банков и банковских систем отражается на конкурентных позициях банков.
\end{abstract}

\footnotetext{
${ }^{*}$ Corresponding author

E-mail addresses: kmm@kneu.edu.ua (I.O. Jusko)
} 
Усиление макропруденциального банковского надзора, широкое применение информационно-инновационных технологий, финансовых инноваций обусловило формирование новой финансовой инфраструктуры имеет последствия международной конкурентоспособности банков на глобальном финансовом рынке (в отдельных случаях открывает перспективы, а в других - создает угрозу или ослабляет конкурентные позиции банка). Учитывая значительное общественное значение глобального банкинга исследования международной конкурентоспособности банков в условиях формирования новой финансовой инфраструктуры приобретает особую актуальность.

\section{2. Материалы и методы}

Исследование базируется на комплексе общих и специальных методов, которые отражают основные научные принципы оценки международной конруентоспособности банка. Использование эмпирических методов исследования дало возможность проверить современные теоретические концепции международной конкурентоспособности банков в условиях формирования новой финансовой инфраструктуры.

В качестве материалов исследования в статье выступают данные тридцати банков, которые осуществляют международную деятельность и включены в список Форбс Глобал 2000 (2016) в качестве основных банков (англ. Major Banks): ICBC, JPMorgan Chase, Wells Fargo, Bank of America, Citigroup, HSBC Holdings, BNP Paribas, Banco Santander, Royal Bank of Canada, Commonwealth Bank, Westpac Banking Group, ANZ, National Australian Bank, Bank of Nova Scotia, US Bancorp, Mizuho Financial, Société Générale, Bank of Montreal, PNC Financial Services, Bank of New York Mellon, Lloyds Banking Group, BB\&T, Natixis, Barclays, Royal Bank of Scotland, FirstRand, Standard Chartered, Regions Financial, KeyCorp, Comerica. Среди них четырнадцать банков включены в 2015 году Советом по финансовой стабильности и Базельским комитетом по финансовому надзору в список системно важных банков мира (ICBC, JPMorgan Chase, Wells Fargo, Bank of America, Citigroup, HSBC Holdings, BNP Paribas, Banco Santander, Mizuho Financial, Société Générale, Bank of New York Mellon, Barclays, Royal Bank of Scotland, Standard Chartered).

Для анализа международной конкурентоспособности рассмотрены как абсолютные показатели в млрд долл. США (чистая прибыль, выручка, величина активов, и рыночная стоимость), так и относительные показатели (рентабельность продаж, рентабельность активов, общий коэффициент дееспособности, рентабельность капитала).

Проведена традиционным способом стандартизация данных (отношение отклонения от средней к стандартному отклонению). Построены и проанализированы интегральные оценки по абсолютным и относительным показателям международной конкурентоспособности банков, осуществлена статистическая обработка данных в Excel.

\section{3. Обсуждение}

Исследование международной конкурентоспособности банков вызывает интерес ученых на современном этапе развития мировой экономики. В частности. А. С. Криклий, И. А. Лютый, А. М. Юрчук выявили диалектическую взаимосвязь категорий эффективности и конкурентоспособности банков [1]. Н. Ю. Гладинець, В. В. Петрина проанализировали и систематизировали современные научные труды относительно трактовки понятия «конкурентоспособность коммерческого банка» [2].

Существуют многочисленные исследования конкуренции на рынках банковских услуг в странах с разным уровнем экономического развития. А. Мирзаэи и Т. Мур подробно изучили движущие силы конкурентного поведения в банковском секторе 146 стран за период 1999-2011 гг. Данное исследование выделяет особенности конкуренции в банковском секторе в группах стран с разным уровнем дохода (развитые страны, страны с формирующимися рынками, развивающиеся страны) [3]. А. Демиргус-Кунт, Л. Лаевен, Р. Левинэ [4], М. Д. Делис [5] исследовали данную тематику для стран Центральной и Восточной Европы, Б. Н. Йеон, М. П. Оливера, И. Ву выявили факторы роста конкуренции иностранных банков в странах Азии и Латинской Америки [6]. 
Влияние финансовых инноваций на конкурентоспособность в банковском секторе еще малоизученоучеными. В частности, К. Бейджнен и В. Болт рассмотрели экономию от масштаба в европейской обработке платежей на основе новейших платежных технологий, среди которых технология распределенных регистров [7]. Значительное внимание зарубежные исследователи уделили влиянию новых финансовых технологий на преобразование финансовой инфраструктуры. Так, Д. Кэмпбелл и Ф.Фрай проанализировали структуру затрат, прибыльность клиентов, стоимость содержания и последствия самообслуживания банковских on-line каналов дистрибуции [8]. М. Ксу, Л. Хит и Р. Чен выделили блокчейн среди определяющих факторов и последствий внедрения интернет-банкинга [9]. Д. Ален и Дж. Т. МакДоналд исследовали границы применения блокчейн-технологии с точки зрения предпринимательства и перспектив банковского дела [10]. В. В. Казаков, А. Г. Ивасенко изучали проблемы и перспективы внедрения финансовых инноваций в разрезе тенденций развития финансовых рынков [11]. Отметим существенный задел украинских исследователей в вопросах использования криптовалют, в частности эти аспекты освещали В. Лукьянов [12], В. Мазур и О. Иванкевич [13], Н. Пантелеева [14], А. Сейтым [15].

Значительный научный потенциал касается изучению финансовой инфраструктуры, ее современного состояния и перспектив развития. В частности, отметим работы О. Иваницкой [16], С. Лёвочкина, В. Опарина и В. Федосова [17], экспертов Мирового банка [18] и др. Государственное регулирование рынков финансовых услуг в условиях функционирования виртуальных валют исследованы в работе Р. Бачо [19]. Д. Кэмпбелл и $\Phi$. Фрей изучали структуру затрат, прибыльность клиентов и последствия внедрения банковских каналов онлайн самообслуживания [20].

Вместе с тем, в научной литературе не достаточного рассмотрены вопросы международной конкурентоспособности банков в условиях формирования новой финансовой инфраструктуры, что определило цель и задачи исследования.

\section{4. Результаты}

Международная конкурентоспособность банка определяется в современном мире возможностью гибко реагировать на формирование новой финансовой инфраструктуры. В. Коваленко отмечает, что трактование понятия «банковская конкуренция» выходит за рамки чисто банковской деятельности «поскольку банковские учреждения конкурируют не только между собой, но и с другими финансовыми и нефинансовыми институтами (кредитные союзы, инвестиционные фонды, негосударственные пенсионные фонды, валютные брокеры, страховые компании, лизинговые и факторинговые компании, торговые организации, фондовые биржи и т. д.) [21, с. 35].

Новые финансовые инструменты имеют чрезвычайно широкие функциональные возможности. Например, применение блокчейн-технологии и децентрализованных реестров для функционирования первой в мире криптовалюты биткоин (англ. Bitcoin) c 2008 года. Финансовые технологии на основе применения Интернет и блокчейна позволяют, с одной стороны, снизить трансакционные издержки, а с другой - повысить прозрачность и безопасность финансовых операций без учета национальной принадлежности субъекта трансакции, что в совокупности способствует более эффективному перераспределению мирового капитала. В 2015 году суммарные инвестиции в финансовые технологии превысили 5 миллиардов долларов. Внедрение инноваций является одним из факторов повышения международной конкурентоспособности банков. Типология банковских инноваций представлена на рис. 1 [11].

В отчете, подготовленном совместно Santander InnoVentures Fund, Oliver Wyman, Anthemis Group, эксперты прогнозируют снижение инфраструктурных расходов банков на 15-20 млн в год до 2022 года. Испанский банк Santander планирует использовать блокчейн в двух десятках рабочих процессов внутри банка [22]. 
Перспективы использования блокчейн-технологии активно изучают JPMorgan Chase, IBM, Microsoft. Например, создание платформы Ефириум (англ. Ethereum) упростило разработку и использование децентрализованных он-лайн сервисов. На рис. 2 представлена схема, которая отражает взаимосвязь формирования новой финансовой инфраструктуры и международной конкурентоспособности банков.

Данную возможность активно используют такие THК, как Microsoft и IBM, что, в свою очередь, влияет на их финансовое положение [23], а значит определяет спрос на банковские услуги.

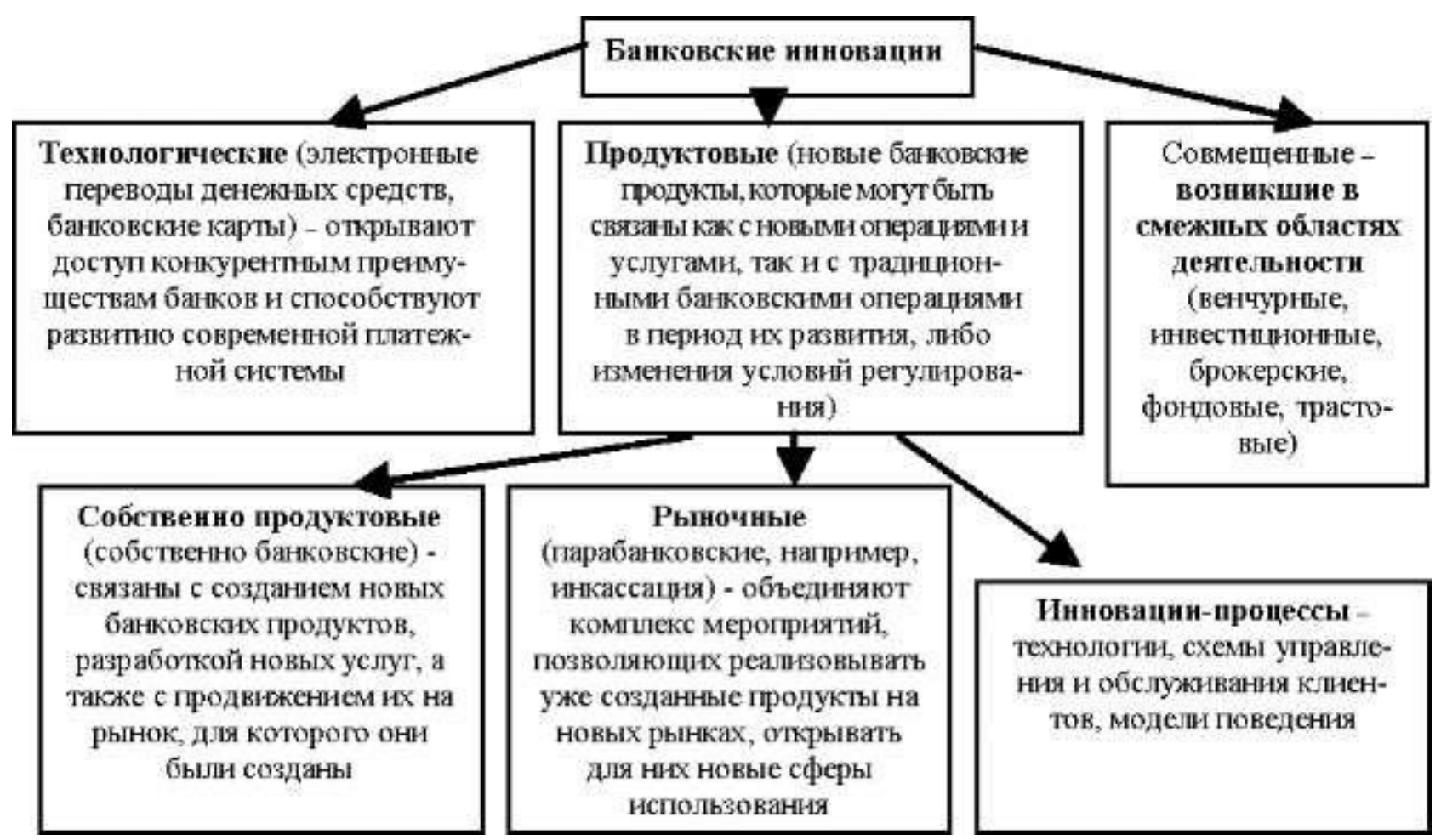

Рис. 1. Типология банковских инноваций.

Источник: [11, с. 40]. 


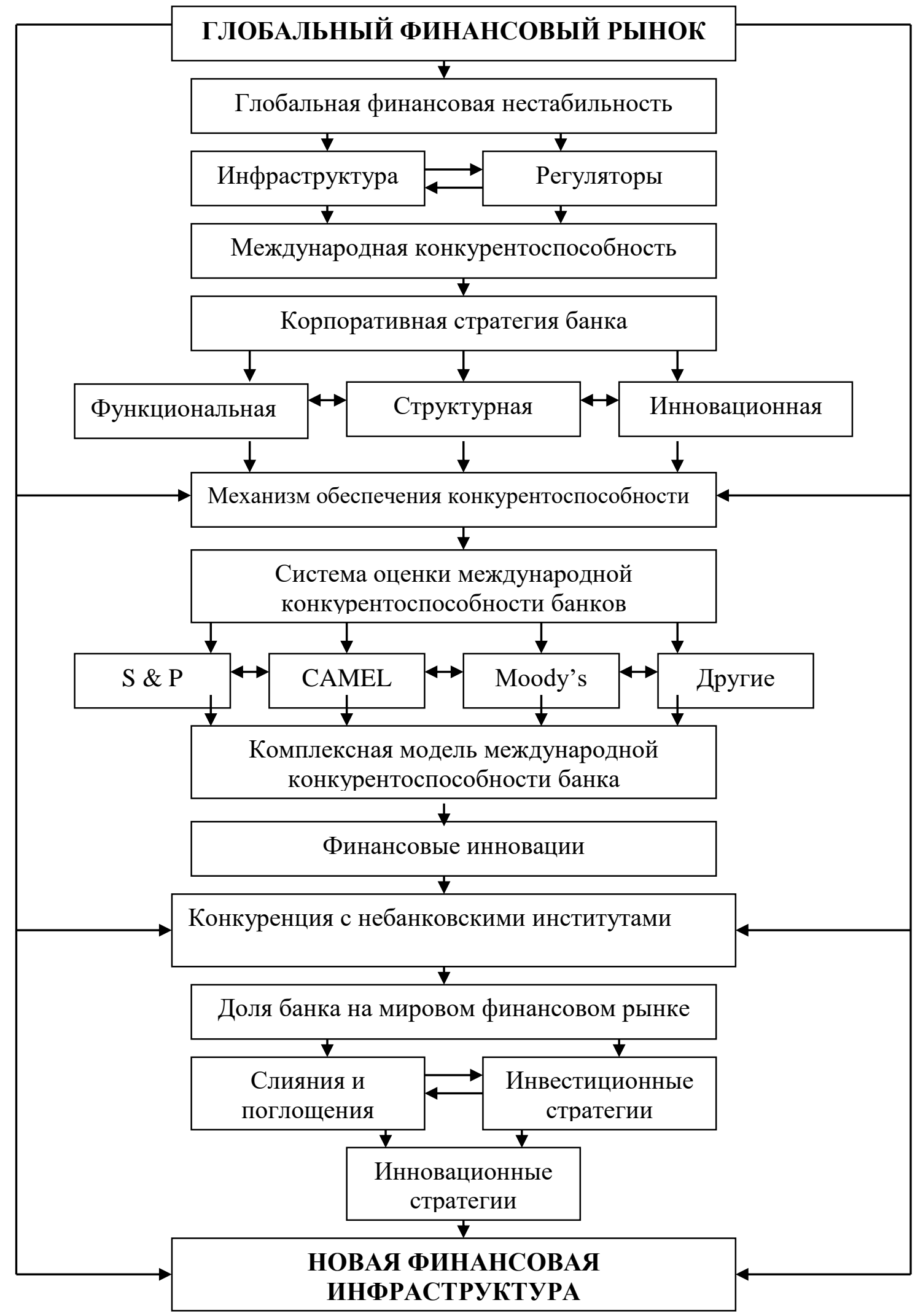

Рис. 2. Взаимосвязь формирования новой финансовой инфраструктуры и международной конкурентоспособности банков. Источник: составлено на основе [24, с.4]. 
В связи с повышенной ролью эффективности банковского менеджмента в условиях формирования новой финансовой инфраструктуры нами предложено использовать матрицу эффективности менеджмента для оценки международной конкурентоспособности банков. Критериями выделения секторов являются высокие или низкие показатели рентабельности и общего коэффициента дееспособности. Чем выше рентабельность активов, тем более эффективно менеджмент банка управляет активами. Общепринятым является критерий рентабельности активов на уровне $1 \%$ и выше. Высокий общий коэффициент дееспособности банка, наоборот свидетельствует о необходимости высоких затрат для получения дохода (выручки банка), т. е., чем ниже этот показатель, тем меньший процент расходов требуется для обеспечения банковской деятельности. Критерием приемлемого показателя общей дееспособности является 85\% и ниже. Общий вид такой матрицы представлен на рис. 3.

\begin{tabular}{|c|c|c|c|}
\hline & \multicolumn{3}{|c|}{ Рентабельность активов банка } \\
\hline \multirow{3}{*}{$\begin{array}{c}\text { Общий } \\
\text { коэффициент } \\
\text { дееспособности } \\
\text { банка }\end{array}$} & & Низкая (ниже 1\%) & Высокая (выше 1\%) \\
\hline & $\begin{array}{l}\text { Низкий } \\
\text { (ниже } \\
85 \% \text { ) }\end{array}$ & $\begin{array}{l}\text { Низкая рентабельность } \\
\text { активов при низкой } \\
\text { затратности }\end{array}$ & $\begin{array}{l}\text { Высокая эффективность } \\
\text { менеджмента банка } \\
\text { Высокая } \\
\text { активов рентабельность } \\
\text { затратности }\end{array}$ \\
\hline & $\begin{array}{l}\text { Высокий } \\
\text { (выше } \\
85 \% \text { ) }\end{array}$ & $\begin{array}{l}\text { Низкая } \\
\text { эффективность } \\
\text { менеджмента банка } \\
\text { Низкая рентабельность } \\
\text { активов при высокой } \\
\text { затратности }\end{array}$ & \begin{tabular}{lr} 
Высокая & \multicolumn{2}{c}{ рентабельность } \\
активов при \\
затратности
\end{tabular} \\
\hline
\end{tabular}

Рис. 3. Общий вид матрицы эффективности банковского менеджмента. Источник: составлено автором.

На основе относительных показателей рентабельности активов и коэффициента общей дееспособности, рассчитанных в процентах на основе данных [25] построена матрица эффективности менеджмента банка для тридцати крупнейших банков мира, имеющих высокую кросс-юрисдикционную активность (рис. 4). 


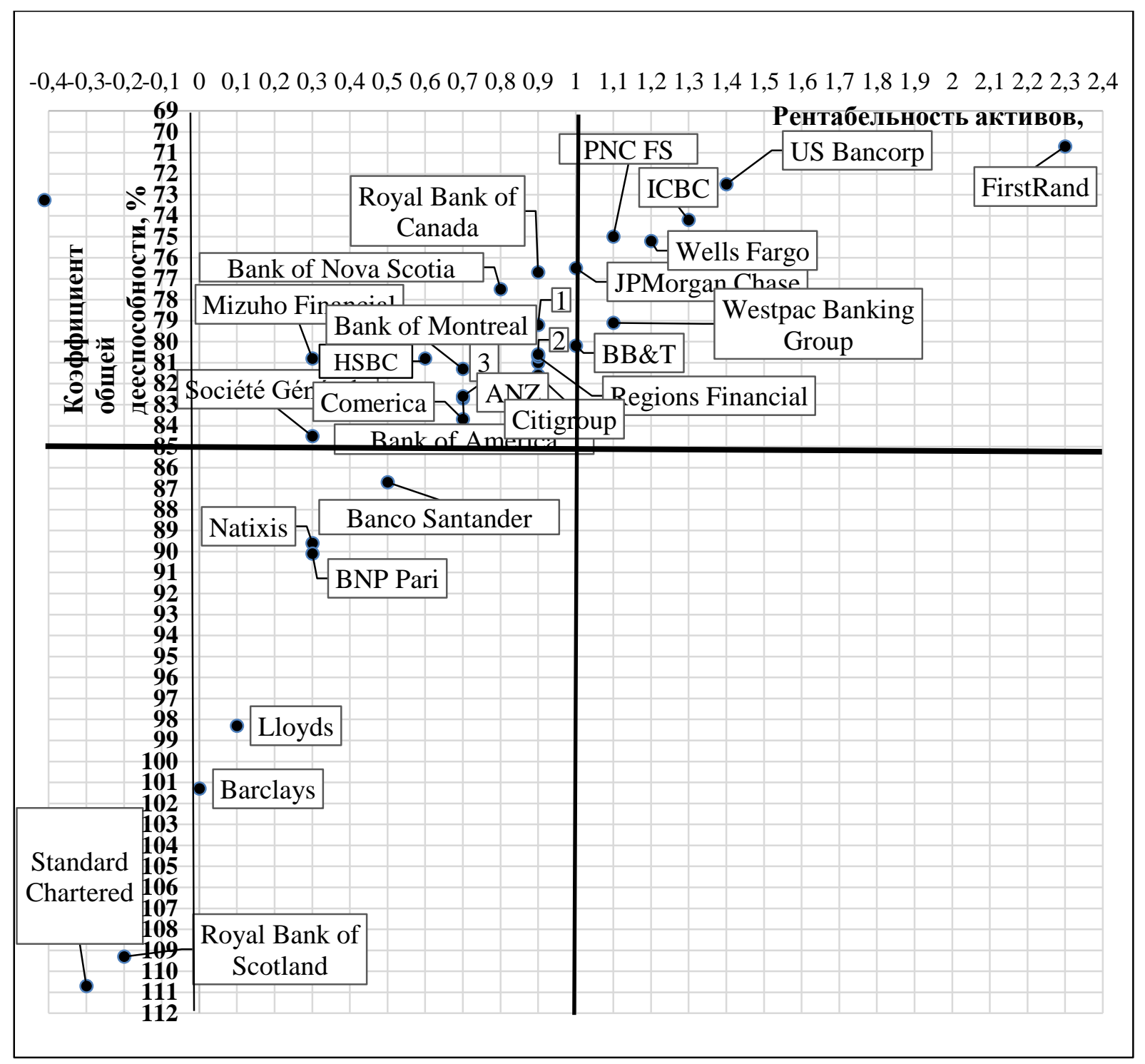

1 - Bank of New York Mellon;

2 - KeyCorp;

3 - National Australian Bank

Рис. 4. Матрица эффективности менеджмента банка.

Источник: рассчитано и построено автором по данным [25].

В сектор высокой эффективности менеджмента банка вошли 8 банков из них только 3 системно важных (Wells Fargo, ICBC, JPMorgan Chase), BB\&T, PNC Financial Services, FirstRand, US Bancorp, Westpac Banking Group. Лучшие значения с большим отрывом имеет южноафриканский FirstRand.

B сектор низкой эффективности менеджмента банка вошли 7 банков. Из них 5 системно важных (Standard Chartered, Royal Bank of Scotland, Barclays, Banco Santander, BNP Paribas) и 2 из списка исследуемых банков Lloyds Banking Group, Natixis. Причем наихудшие показатели имели 2 системно важных банка Великобритании - Standard Chartered, Royal Bank of Scotland.

Остальные 15 банков попали в сектор низкой рентабельности, но и низкой затратности (Bank of America, Citigroup, HSBC Holdings, BNP Paribas, Banco Santander, Royal Bank of Canada, Commonwealth Bank, ANZ, National Australian Bank, Bank of Nova Scotia, Mizuho Financial, Société Générale, Bank of Montreal, Bank of New York Mellon, Barclays, Royal Bank of Scotland, Standard Chartered, Regions Financial, KeyCorp, Comerica. Среди них четырнадцать 
банков системно важных банков мира (Bank of America, Citigroup, HSBC Holdings, Mizuho Financial, Société Générale, Bank of New York Mellon).

Ни один банк из тридцати исследуемых не попал в сектор высокой рентабельности при высокой затратности.

Некоторые авторы при оценке конкурентоспособности банков делают акцент на абсолютных финансовых показателях и величине рыночной доли банка, другие - на относительных показателях, которые нивелируют величину банка, третьи - используют сочетание абсолютных и относительных показателей при расчете интегральных показателей и при построении матриц конкурентоспособности. Расчет интегральных показателей по абсолютным и относительным значениям свидетельствует о существенных различиях.

В таблице 1 представлены результаты расчета стандартизированных показателей абсолютных значений прибыли, выручки, активов и рыночной стоимости тридцати крупнейших банков мира. Поскольку при более высоких показателях относительно среднего знак отрицательный, то отрицательное значение интегрального показателя свидетельствует о более высокой конкурентоспособности банка.

Таблица 1. Стандартизированные показатели абсолютных значений прибыли, выручки, активов и рыночной стоимости тридцати крупнейших банков мира

\begin{tabular}{|c|c|c|c|c|c|}
\hline Название банка & 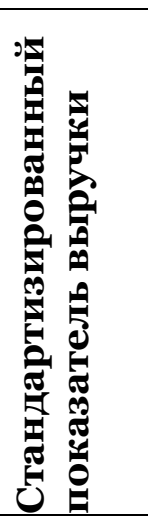 & 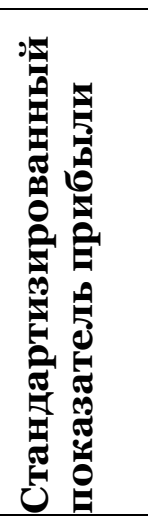 & 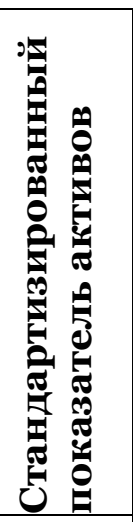 & 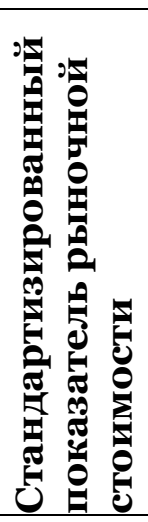 & 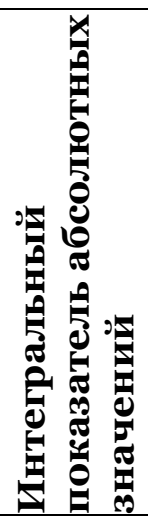 \\
\hline$I C B C *$ & $-3,56$ & $-4,02$ & $-2,77$ & $-1,94$ & $-3,07$ \\
\hline JPMorgan Chase* & $-1,62$ & $-1,77$ & $-1,59$ & $-2,51$ & $-1,87$ \\
\hline Wells Fargo* & $-1,39$ & $-1,68$ & $-0,91$ & $-2,85$ & $-1,71$ \\
\hline Bank of America* & $-1,39$ & $-0,93$ & $-1,31$ & $-1,27$ & $-1,23$ \\
\hline Citigroup* & $-1,24$ & $-0,93$ & $-0,86$ & $-0,99$ & $-1,01$ \\
\hline HSBC Holdings $*$ & $-0,81$ & $-0,68$ & $-1,58$ & $-0,91$ & $-1,00$ \\
\hline BNP Paribas* & $-0,94$ & $-0,02$ & $-1,29$ & 0,13 & $-0,53$ \\
\hline Banco Santander* & $-0,25$ & 0,07 & $-0,45$ & 0,04 & $-0,15$ \\
\hline Royal Bank of Canada & 0,20 & $-0,05$ & 0,26 & $-0,25$ & 0,04 \\
\hline Commonwealth Bank & 0,20 & 0,03 & 0,50 & $-0,38$ & 0,09 \\
\hline Westpac Banking Group & 0,28 & 0,10 & 0,60 & $-0,09$ & 0,22 \\
\hline ANZ & 0,26 & 0,14 & 0,53 & 0,32 & $\mathbf{0 , 3 1}$ \\
\hline National Australian Bank & 0,32 & 0,24 & 0,48 & 0,29 & $\mathbf{0 , 3 3}$ \\
\hline Bank of Nova Scotia & 0,44 & 0,18 & 0,50 & 0,21 & $\mathbf{0 , 3 3}$ \\
\hline US Bancorp & 0,53 & 0,15 & 0,77 & 0,00 & 0,36 \\
\hline Mizuho Financial* & 0,40 & 0,24 & $-0,65$ & 0,54 & $\mathbf{0 , 1 3}$ \\
\hline Société Générale* & 0,33 & 0,30 & $-0,44$ & 0,67 & 0,22 \\
\hline Bank of Montreal & 0,61 & 0,41 & 0,68 & 0,52 & 0,56 \\
\hline PNC Financial Services & 0,67 & 0,35 & 0,85 & 0,49 & 0,59 \\
\hline Bank of New York Mellon* & 0,68 & 0,43 & 0,83 & 0,49 & 0,61 \\
\hline Lloyds Banking Group & $-0,16$ & 0,70 & $-0,13$ & 0,08 & $\mathbf{0 , 1 2}$ \\
\hline $\mathrm{BB} \& \mathrm{~T}$ & 0,81 & 0,55 & 1,02 & 0,72 & $\mathbf{0 , 7 8}$ \\
\hline Natixis & 0,71 & 0,62 & 0,63 & 0,91 & 0,72 \\
\hline
\end{tabular}




\begin{tabular}{|l|r|r|r|r|r|}
\hline Barclays* $^{*}$ & 0,04 & 0,84 & $-0,68$ & 0,52 & $\mathbf{0 , 1 8}$ \\
\hline Royal Bank of Scotland* $^{*}$ & 0,40 & 1,04 & $-0,15$ & 0,51 & $\mathbf{0 , 4 5}$ \\
\hline FirstRand & 0,95 & 0,60 & 1,19 & 0,89 & $\mathbf{0 , 9 1}$ \\
\hline Standard Chartered* & 0,54 & 1,02 & 0,52 & 0,77 & $\mathbf{0 , 7 1}$ \\
\hline Regions Financial & 0,95 & 0,66 & 1,12 & 1,00 & $\mathbf{0 , 9 3}$ \\
\hline KeyCorp & 0,98 & 0,69 & 1,16 & 1,02 & $\mathbf{0 , 9 6}$ \\
\hline Comerica & 1,03 & 0,73 & 1,19 & 1,06 & $\mathbf{1 , 0 0}$ \\
\hline
\end{tabular}

* системно важный банк мира

Источник: рассчитано автором по данным [25].

В таблице 2 представлены результаты расчета стандартизированных значений относительных значений финансовых показателей тридцати крупнейших банков мира.

Таблица 2. Стандартизированные показатели относительных значений финансовых показателей тридцати крупнейших банков мира

\begin{tabular}{|c|c|c|c|c|c|c|c|}
\hline Название банка & 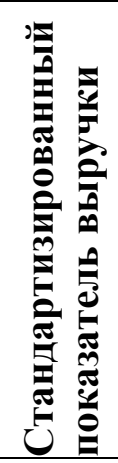 & 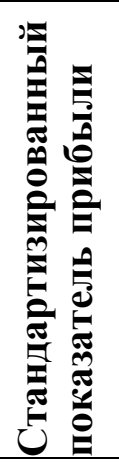 & 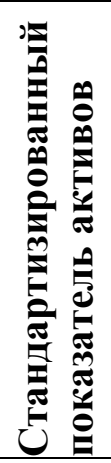 & 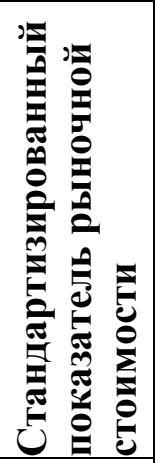 & $\begin{array}{ll} \\
\end{array}$ & 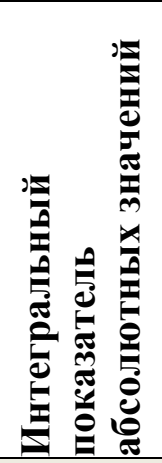 & 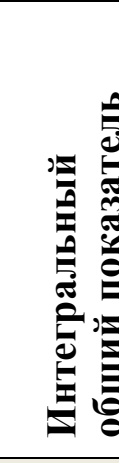 \\
\hline$I C B C^{*}$ & $-0,94$ & $-0,94$ & $-1,18$ & $-2,58$ & $-0,86$ & $-3,07$ & $-1,965$ \\
\hline JPMorgan Chase* & $-0,71$ & $-0,71$ & $-0,54$ & $-0,38$ & $-0,21$ & $-1,87$ & $-1,04$ \\
\hline Wells Fargo* & $-0,84$ & $-0,84$ & $-1,06$ & $-0,17$ & $-0,32$ & $-1,71$ & $-1,015$ \\
\hline Bank of America* & $-0,07$ & $-0,07$ & $-0,05$ & $-0,40$ & $\mathbf{0 , 1 3}$ & $-1,23$ & $-0,55$ \\
\hline Citigroup* & $-0,18$ & $-0,18$ & $-0,35$ & $-0,63$ & $-0,02$ & $-1,01$ & $-0,515$ \\
\hline HSBC Holdings* & $-0,27$ & $-0,27$ & 0,28 & $-0,40$ & $\mathbf{0 , 1 2}$ & $-1,00$ & $-0,44$ \\
\hline BNP Paribas* & 0,69 & 0,69 & 0,72 & $-0,57$ & $\mathbf{0 , 5 3}$ & $-0,53$ & $\mathbf{0}$ \\
\hline Banco Santander* & 0,34 & 0,34 & 0,49 & $-0,21$ & 0,42 & $-0,15$ & $\mathbf{0 , 1 3 5}$ \\
\hline Royal Bank of Canada & $-0,68$ & $-0,68$ & $-0,41$ & $-0,11$ & $-0,11$ & 0,04 & $-0,035$ \\
\hline Commonwealth Bank & $-0,43$ & $-0,43$ & $-0,70$ & 0,17 & $-0,03$ & 0,09 & $\mathbf{0 , 0 3}$ \\
\hline Westpac Banking Group & $-0,43$ & $-0,43$ & $-0,81$ & 0,01 & $-0,08$ & 0,22 & $\mathbf{0 , 0 7}$ \\
\hline ANZ & $-0,24$ & $-0,24$ & $-0,49$ & $-0,51$ & $-0,05$ & 0,31 & $\mathbf{0 , 1 3}$ \\
\hline National Australian Bank & $-0,08$ & $-0,08$ & $-0,09$ & $-0,17$ & $\mathbf{0 , 1 6}$ & 0,33 & 0,245 \\
\hline Bank of Nova Scotia & $-0,61$ & $-0,61$ & $-0,28$ & $-0,18$ & $-0,08$ & $\mathbf{0 , 3 3}$ & 0,125 \\
\hline US Bancorp & $-1,11$ & $-1,11$ & $-1,31$ & 0,03 & $-0,42$ & 0,36 & $-0,03$ \\
\hline Mizuho Financial* & $-0,27$ & $-0,27$ & 0,78 & $-0,78$ & $\mathbf{0 , 1 4}$ & 0,13 & $\mathbf{0 , 1 3 5}$ \\
\hline Société Générale* & 0,11 & 0,11 & 0,79 & $-1,01$ & $\mathbf{0 , 2 4}$ & 0,22 & 0,23 \\
\hline Bank of Montreal & $-0,21$ & $-0,21$ & 0,03 & $-0,04$ & 0,16 & 0,56 & $\mathbf{0 , 3 6}$ \\
\hline PNC Financial Services & $-0,86$ & $-0,86$ & $-0,82$ & $-0,21$ & $-0,28$ & 0,59 & 0,155 \\
\hline Bank of New York Mellon* & $-0,43$ & $-0,43$ & $-0,32$ & 0,12 & 0,04 & $\mathbf{0 , 6 1}$ & $\mathbf{0 , 3 2 5}$ \\
\hline Lloyds Banking Group & 1,52 & 1,52 & 1,27 & 1,21 & 1,31 & 0,12 & $\mathbf{0 , 7 1 5}$ \\
\hline BB\&T & $-0,33$ & $-0,33$ & $-0,58$ & 0,12 & $\mathbf{0 , 0 3}$ & 0,78 & 0,405 \\
\hline Natixis & 0,63 & 0,63 & 0,85 & $-0,15$ & $\mathbf{0 , 6 2}$ & 0,72 & 0,67 \\
\hline
\end{tabular}




\begin{tabular}{|l|r|r|r|r|r|r|r|}
\hline Barclays* $^{*}$ & 1,82 & 1,82 & 1,46 & 1,62 & $\mathbf{1 , 5 4}$ & $\mathbf{0 , 1 8}$ & $\mathbf{0 , 8 6}$ \\
\hline Royal Bank of Scotland $^{*}$ & 2,64 & 2,64 & 1,80 & 2,42 & $\mathbf{2 , 0 8}$ & $\mathbf{0 , 4 5}$ & $\mathbf{1 , 2 6 5}$ \\
\hline FirstRand & $-1,30$ & $-1,30$ & $-3,23$ & $-0,23$ & $\mathbf{- 0 , 9 3}$ & $\mathbf{0 , 9 1}$ & $\mathbf{- 0 , 0 1}$ \\
\hline Standard Chartered & 2,79 & 2,79 & 2,09 & 2,90 & $\mathbf{2 , 2 9}$ & $\mathbf{0 , 7 1}$ & $\mathbf{1 , 5}$ \\
\hline Regions Financial & $-0,28$ & $-0,28$ & $-0,35$ & $-0,24$ & $\mathbf{0 , 0 2}$ & $\mathbf{0 , 9 3}$ & $\mathbf{0 , 4 7 5}$ \\
\hline KeyCorp & $-0,28$ & $-0,28$ & $-0,37$ & $-0,08$ & $\mathbf{0 , 0 4}$ & $\mathbf{0 , 9 6}$ & $\mathbf{0 , 5}$ \\
\hline Comerica & 0,03 & 0,03 & 0,08 & 0,35 & $\mathbf{0 , 3 4}$ & $\mathbf{1 , 0 0}$ & $\mathbf{0 , 6 7}$ \\
\hline
\end{tabular}

Источник: рассчитано автором по данным [25].

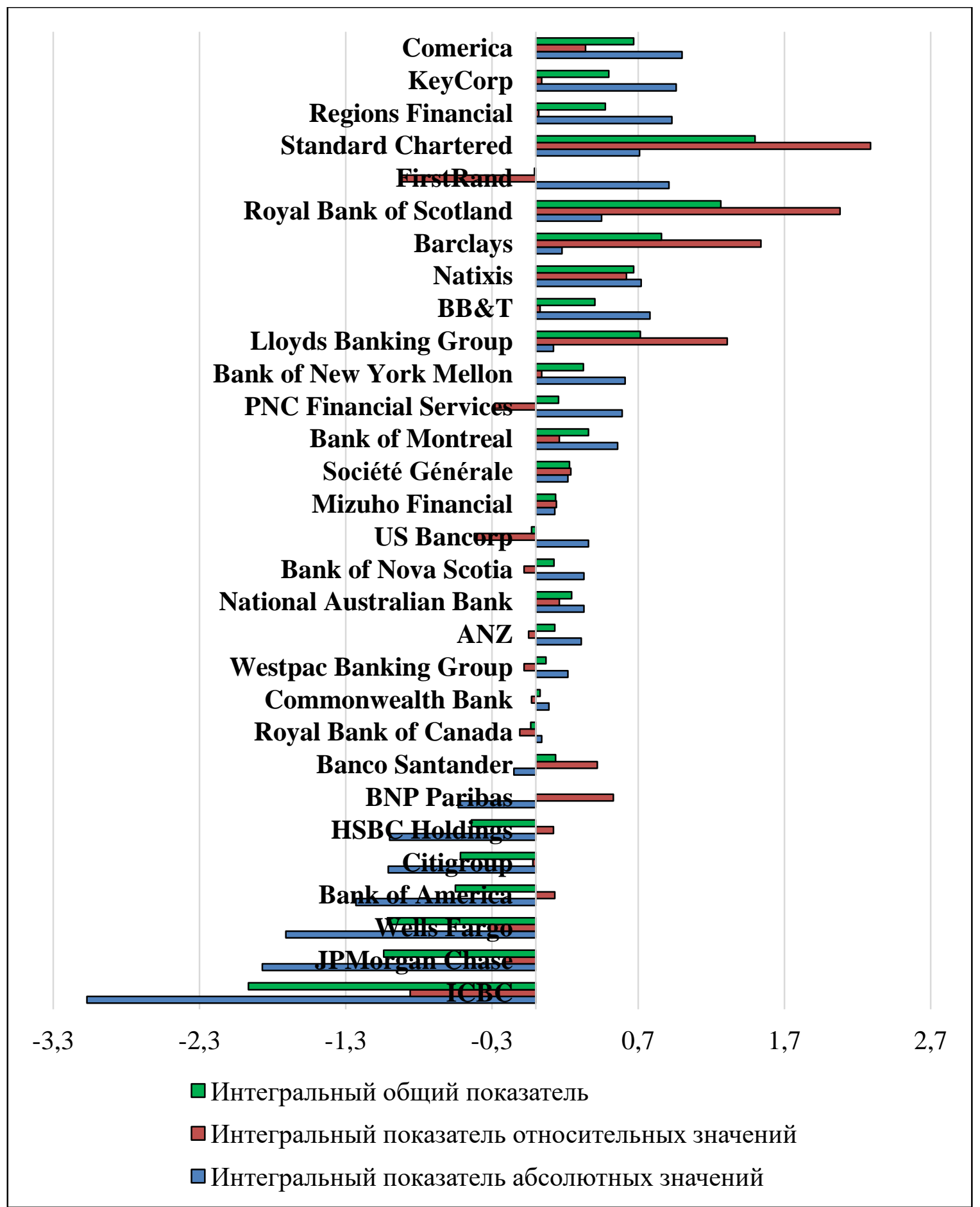

Pис. 5. Международная конкурентоспособность выбранных банков на основе интегральных оценок. Источник: рассчитано и построено автором по данным табл. 2. 
Системно важные банки мира, включенные в анализ, демонстрируют более высокие значения интегрального показателя по абсолютным значениям, однако уступают конкурентам на глобальном финансовом рынке по интегральному показателю относительных значений (рис. 5).

Только четыре системно важных банка (ICBC, JPMorgan Chas, Wells Fargo) являются лидерами мировой банковской системы и по абсолютным, и по относительным значениям. Если судить по интегральному общему показателю, то конкурентными являются 9 банков, в том числе 6 системно важных (ICBC, JPMorgan Chase, Wells Fargo, Bank of America, Citigroup, HSBC Holdings), и 2 банка, являющихся лидерами по показателям эффективности банковского менеджмента (FirstRand и US Bancorp) и 1 банк, который имеет средние показатели эффективности менеджмента (Royal Bank of Canada).

\section{5. Заключение}

Усиление макропруденциального банковского надзора, широкое применение информационно-инновационных технологий, финансовых инноваций являются современными факторами формирования новой финансовой инфраструктуры, что имеет последствия для международной конкурентоспособности банков на глобальном финансовом рынке. На основе обобщения современных теоретических разработок рассчитаны интегральные показатели конкурентоспособности банков, имеющих высокую кроссюрисдикционную активность. Масштабы деятельности определяют конкурентное преимущество по абсолютным показателям основных банков. Так, в 2015 лидером был системно важный банк мира Промышленный и коммерческий банк Китая (ICBC), который имел высокие значения чистой прибыли, выручки и величины активов. Однако по относительным показателям этот банк опережает конкурентов только по уровню рентабельности капитала. По относительным показателям системно важные банки демонстрируют в основном более низкие показатели, чем другие основные банки в 2015 году. Наиболее высокие относительные показатели и показатели эффективности банковского менеджмента имел южноафриканский FirstRand. Расчет интегральных показателей и построение матрицы эффективности банковского менеджмента продемонстрировали возможности выполнить требования «Базеля-III» при высоком качестве управления расходами и активами (сектор высокой эффективности менеджмента банка) основных банков. Только четыре системно важных банка (ICBC (Китай) и JPMorgan Chase (США), Citigroup (США), Wells Fargo (США)) из четырнадцати исследованных являются лидерами мировой банковской системы и по абсолютным, и по относительным финансовым показателям.

\section{Примечания}

1. Криклій А. С. Конкурентоспроможність і ефективність як критерії економічної спроможності банків на ринку фінансових послуг / А. С. Криклій, І. О. Лютий, О. М. Юрчук // Економіка та держава. 2008. №11. С.16-19.

2. Гладинець Н. Ю. Конкурентоспроможність комерційного банку: теоретичні аспекти та підходи до визначення / Н. Ю. Гладинець, В.В. Петрина // Глобальні та національні проблеми економіки. Вісник №4. 2015. С. 814-818.

3. Mirzaei A. What are the driving forces of bank competition across different income groups of countries? / A. Mirzaei,T. Moore // Journal of International Financial Markets, Institutions and Money. Volume 32, September 2014. Pp. 38-71.

4. Demirguc-Kunt A. Regulations, market structure, institutions, and the cost of financial intermediation / A. Demirguc-Kunt, L. Laeven, R. Levine // Journal of Money, Credit and Banking. 2004. 36. Pp. 593-622.

5. Delis, M.D. Bank competition, financial reform, and institutions: the importance of being developed. Journal of Development Economics. 2012. 97. Pp. 450-465.

6. Jeon B. N. Do foreign banks increase competition? Evidence from emerging Asian and Latin American banking markets / Jeon, B. N., Olivero, M. P., Wu J. // Journal of Banking and Finance. 2011. 35 (4), 856-875. 
7. Beijnen C. Size Matters: Economies of Scalein European Payments Processing / Beijnen C. and W. Bolt //Journal of Banking\&Finance. 2009. 33 (2). pp. 203-210.

8. Campbell D. Cost Structure, Customer Profitability, and Retention Implications of SelfService Distribution Channels: Evidence from Customer Behavior in an Online Banking Channel / Campbell, D. and F. Frei // Management Science. 2010. 56 (1). 4-24.

9. Xue M. Determinants and Outcomes of Internet Banking Adoption / M. Xue, L. M. Hittand, P. Chen // Management Science. 2011. 57(2). 291-307.

10. Allen D. 'The economic organisation of the entrepreneurial problem of blockchains' / Allen D., MacDonald T. J. (2016) [online] available at: http://ssrn.com/abstract=2749018.

11. Казаков В. В. Проблемы и перспективы внедрения финансовых инноваций в разрезе тенденций развития финансовых рынков / В.В.Казаков, А. Г. Ивасенко // Проблемы учета и финансов. 2014. №3 (15). С.36-41.

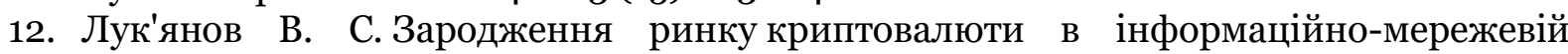
парадигмі [Електронний ресурс] / В. С. Лук'янов // Актуальні проблеми економіки. - 2014. № 8. C. 436-441. Режим доступа: http: //nbuv.gov.ua/UJRN/ape_2014_8_54

13. Мазур В. Особливості використання криптовалюти в світі та в Україні / В. Мазур, О. Іванкевич // Проблеми інформатизації та управління. 2016. №1. [Електронний ресурс]. Режим доступу: www.nau.edu.ua.

14. Пантєлєєва Н. Нові форми грошей в умовах формування інформаційного суспільства / Н. Пантєлєєва // Вісник Національного банку України. №5. 2015.

15. Сейтим А.Е. Использование криптовалют как альтернативное решение проблем мировой валютной системы [Електронний ресурс] / А. Е. Сейтим // Проблеми економіки. 2014. № 2. C. 50-55. - Режим доступа: http://nbuv.gov.ua/UJRN/Pekon_2014_2_7

16. Іваницька О.M. Державне регулювання розвитку фінансової інфраструктури : Моногр. / О. М. Іваницька. К., 2005. 275 с.

17. Фінансова інфраструктура ринкової економіки: концептуальні підходи / С. Льовочкін, В. Опарін, В. Федосов // Економіка України. 2008. № 11. С. 57-71.

18. Financial Infrastructure Building Access Through Transparent and Stable Financial Systems. Financial Infrastructure Policy And Research Series. A publication of the World Bank and the International Finance Corporation. Washington, The Worl dBank, 2009. 26 p.

19. Бачо Р.Й. Державне регулювання ринків фінансових послуг в умовах функціонування віртуальних валют (криптовалют) [Електронний ресурс] / Р. Й. Бачо // Бізнес Інформ. 2015. № 11. С. 294-298.

20. Campbell D. Cost Structure, Customer Profitability, and Retention Implications of Self-Service Distribution Channels: Evidence from Customer Behavior in an Online Banking Channel / Campbell, D. and F. Frei // Management Science. 2010. 56(1). 4-24.

21. Коваленко В. В. Достатність капіталу банківської системи в умовах циклічного розвитку економіки / В. В. Коваленко, Я. Е. Вербицкая / / International Scientific and Practical Conference "WORLD SCIENCE"'. № 1(5), Vol.5, January 2016. C. 35-38.

22. The Fintech 2.o Paper: rebooting financial services https://www.finextra.com /finextradownloads/newsdocs/the\%20fintech\% 202\%200\%20 paper.pdf

23. Гальперіна Л. П. Фінансові чинники стратегій ТНК на глобальному IT-ринку / Л. П. Гальперіна, Л. І. Лук’яненко, А. Ю. Яценко // Інвестиції: практика і досвід. 2015. № 24. С. $89-94$.

24. Коваль В. В. Глобальна конкурентоспроможність транснаціональних банків: автореф. дис. ... канд. екон. наук: 08.0о.02 / В. В. Коваль; ДВНЗ «КНЕУ ім. В. Гетьмана». К., 2012. $21 \mathrm{c}$.

25. Forbes 2016. The World's Biggest Public Companies. Available from: http://www.forbes.com/global200o/list

\section{References}

1. Kry`klij A. S. (2008). Konkurentospromozhnist`i efekty`vnist` yak kry`teriyi ekonomichnoyi spromozhnosti bankiv na ry`nku finansovy`x poslug [Competitiveness and efficiency as criteria of economic viability of banks in the financial services] / A. S. Kry `klij, I. O. Lyuty j, O. M. Yurchuk // Ekonomika ta derzhava. 2008. 11. Pp.16-19. 
2. Glady`necz` N. Yu. (2015). Konkurentospromozhnist` komercijnogo banku: teorety `chni aspekty` ta pidxody` do vy`znachennya [Commercial Bank Competitiveness: theoretical aspects and approaches to the determination] / N. Yu. Glady`necz `, V. V. Petry`na. Global `ni ta nacional `ni problemy`ekonomiky`[Global and national problems of economy]. Visny`k. №4. Pp. 814-818.

3. Mirzaei A. (2014). What are the driving forces of bank competition across different income groups of countries? / A. Mirzaei, T. Moore // Journal of International Financial Markets, Institutions and Money. Volume 32, September 2014, Pp. 38-71.

4. Demirguc-Kunt A. (2004). Regulations, market structure, institutions, and the cost of financial intermediation / A. Demirguc-Kunt, L. Laeven, R. Levine // Journal of Money, Credit and Banking. 36, pp. 593-622.

5. Delis M. D. (2012). Bank competition, financial reform, and institutions: the importance of being developed // Journal of Development Economics. 97. Pp. 450-465.

6. Jeon B. N. (2011). Do foreign banks increase competition? Evidence from emerging Asian and Latin American banking markets / Jeon B. N., Olivero, M.P., Wu, J., // Journal of Banking and Finance 35 (4), 856-875.

7. Beijnen C. (2009). Size Matters: Economies of Scalein European Payments Processing / Beijnen, C. and W. Bolt // Journal of Banking \& Finance. 33 (2). pp. 203-210.

8. Campbell D. (2010). Cost Structure, Customer Profitability, and Retention Implications of Self-Service Distribution Channels: Evidence from Customer Behavior in an Online Banking Channel / Campbell, D. and F. Frei // Management Science. 56 (1). 4-24.

9. Xue M. (2011). Determinants and Outcomes of Internet Banking Adoption / M. Xue, L. M. Hittand, P. Chen // Management Science. 57(2). 291- 307.

10. Allen D. (2016) "The economic organisation of the entrepreneurial problem of blockchains'/ Allen D., MacDonald T. J. [online] Available from: http://ssrn.com/ abstract $=2749018$.

11. Kazakov V. V. (2014). Problemy i` perspekty`vy vnedreny`ya fy`nansovyh y`nnovacy`j v razreze tendency $\mathrm{j}$ razvy ‘t `ya fy`nansovyh rynkov [Problems and prospects of implementation of financial innovation in the context of development trends in the financial markets] / V. V. Kazakov, A. G. I vasenko // Problemy ucheta y` fy`nansov [Problems of accounting and finance]. № 3 (15). S.36-41.

12. Luk'yanov V. S. Zarodzhennya ry`nku kry`ptovalyuty` $v$ informacijno-merezhevij parady 'gmi [Origin cryptocurrency market in information and network paradigm] [Elektronny ${ }^{`} \mathrm{j}$ resurs] / V. S. Luk'yanov // Aktual `ni problemy` ekonomiky` [Actual problems of economy]. 2014. № 8. S. 436- 441. Available from: http: //nbuv.gov.ua/UJRN/ape_2014_8_54

13. Mazur V. (2016). Osobly`vosti vy`kory`stannya kry`ptovalyuty`v sviti ta v Ukrayini / V. Mazur, O. Ivankevy 'ch [Features of cryptocurrency in the world and in Ukraine] // Problemy` informaty zaciyi ta upravlinnya [Problems of Information and Management]. - \#1. [Elektronny` $\mathrm{j}$ resurs]. Available from: www.nau.edu.ua.

14. Pantyelyeyeva N. (2015). Novi formy` groshej v umovax formuvannya informacijnogo suspil `stva / N. Pantyelyeyeva // Visny`k Nacional `nogo banku Ukrayiny`. №5. 2015.

15. Sejty`m A. E. (2014). Y`spol`zovany`e kry`ptovalyut kak al`ternaty`vnoe resheny`e problem my`rovoj valyutnoj sy`stemы [Elektronny`j resurs] / A. E. Sejty`m // Problemy` ekonomiky`. № 2. S. 50-55. - Available from: http: //nbuv.gov.ua/UJRN/Pekon_2014_2_7

16. Ivany`cz`ka O.M. Derzhavne regulyuvannya rozvy`tku finansovoyi infrastruktury: Monogr. / O. M. Ivany`cz`ka. K., 2005. 275 c.

17. L`ovochkin S. (2008). Finansova infrastruktura ry`nkovoyi ekonomiky`: konceptual `ni pidxody` / S. L`ovochkin, V. Oparin, V. Fedosov // Ekonomika Ukrayiny`. № 11. S. 57-71.

18. Financial Infrastructure Building Access Through Transparent and Stable Financial Systems. Financial Infrastructure Policy And Research Series. A publication of the World Bank and the International Finance Corporation. Washington, The Worl dBank, 2009. 26 p.

19. Bacho R. J. (2015). Derzhavne regulyuvannya ry`nkiv finansovy`x poslug v umovax funkcionuvannya virtual `ny `x valyut (kry`ptovalyut) [State regulation of financial services under conditions of virtual currencies (cryptocurrency)] [electronic resource] / RY Bacho // Business Inform. № 11. P. 294-298. 
20. Campbell D. (2010). Cost Structure, Customer Profitability, and Retention Implications of Self-Service Distribution Channels: Evidence from Customer Behavior in an Online Banking Channel / Campbell, D. and F. Frei // Management Science. 56(1). 4-24.

21. Kovalenko V. V. (2016). Dostatnist` kapitalu bankivs`koyi sy`stemy` v umovax cy 'klichnogo rozvy`tku ekonomiky` / V. V. Kovalenko, Ya. E. Verby`czkaya // International Scientific and Practical Conference "World Science". № 1(5), Vol.5, January 2016. C. 35-38.

22. The Fintech 2.0 Paper: rebooting financial services. Available from: https://www. finextra. com/finextra-downloads/newsdocs/the\%20fintech\%202\%200\%20paper.pdf

23. Galperina L. P. (2015). Finansovi chy`nny`ky`strategij TNK na global `nomu IT-ry`nku [Financial factors TNC strategies in the global IT market] / L. Galperina, L. Lukyanenko, A. Yatsenko // Investments: practice and experience. 2015. 24. S. 89-94.

24. Koval V.V. Global competitiveness of transnational banks. - The Manuscript. A Thesis for the Academic Degree of Candidate of Economic Sciences in specialty 08.00.02 - World Economy and International Economic Relations. - SHEE "Vadym Hetman Kyiv National Economic University”. Kyiv, 2012. 21 p.

25. Forbes 2016. The World's Biggest Public Companies. Available from: http://www.forbes.com/global200o/list

УДК 339.137.2:72+336

\section{Международная конкурентоспособность банков в условиях формирования новой финансовой инфраструктуры}

Игорь Олегович Юшко ${ }^{\text {a }}$ *

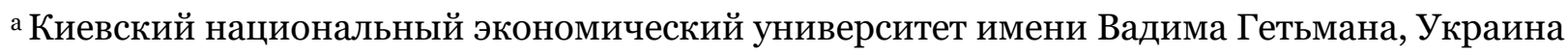

Аннотация. В статье рассмотрены факторы формирования новой финансовой инфраструктуры. Исследованы ключевые факторы международной конкурентоспособности банков в условиях формирования новой финансовой инфраструктуры. Выявлено влияние усиления макропруденциального банковского надзора, широкого применения информационно-инновационных технологий, финансовых инноваций на формирование новой финансовой инфраструктуры, что имеет последствия для международной конкурентоспособности банков на глобальном финансовом рынке. На основе обобщения современных теоретических разработок рассчитаны интегральные показатели конкурентоспособности банков, имеющих высокую кросс-юрисдикционную активность. Особое внимание уделено эффективности банковского менеджмента.

Ключевые слова: финансиализация, глобализация, финансовая инфраструктура, конкурентоспособность, системно важные банки, основные банки, блокчейн-технолгия, транзакции.

\footnotetext{
${ }^{*}$ Корреспондирующий автор

Адреса электронной почты: kmm@kneu.edu.ua (И.О. Юшко)
} 